\title{
Diploma in Psychological Medicine (DPM) at Postgraduate Medical Institute, Lahore
}

\author{
ljaz Haider
}

There are only 130 psychiatrists in Pakistan for a population of 95 million and they are stationed at major cities where only $15 \%$ of the population of the country resides. The foreign trained psychiatrists, mostly in the UK, are attached to the departments of psychiatry of medical schools in major cities and are not willing to go to rural areas where $85 \%$ of the population lives. Thus there is an acute shortage of psychiatrists at district headquarter hospitals (DHQ) in rural areas.

In view of the national programme for promotion of health care, and to achieve the target of 'Health for All by Year 2000', a one year whole-time Diploma course in Psychological Medicine (DPM) was started at the Postgraduate Medical Institue, Lahore, Punjab in 1988-89 to meet the shortage of doctors. Each academic year 20 doctors are admitted to the DPM course of whom ten are on deputation from regular government service where they are already serving in rural areas as general duty medical officers. The remaining ten doctors have not been inducted into government service and are in the private sector as general practitioners or belong to other provinces. The eligibility criteria for admission to the DPM is the MBBS degree from a recognised institution in Pakistan and one year internship in psychiatry in a teaching institution.

The DPM course comprises Part I which lasts for four months and students are examined in neuroanatomy, neurophysiology and psychology related to psychiatry but also attend psychiatric wards for clinical experience, and Part II which includes theoretical knowledge as well as clinical demonstrations in adult psychiatry, neurology, child psychiatry, drug addiction treatment programme, centres for mentally handicapped children and long-stay chronic patients in government mental hospitals, rehabilitation programmes for mentally disabled patients, primary health care services and the District Jail for forensic psychiatry. Psychiatry lectures are conducted at the Department of Psychological Medicine Postgraduate Medical Institute whereas for clinical instruction students are attached by rotation to the clinical departments of psychiatry of the three undergraduate medical colleges in Lahore as well as government mental hospitals, neurology and child \& family psychiatry units. Thus they are exposed and allowed to handle patients in the out-patient and in-patient departments, participate in case conferences, seminars, journal clubs, psychotherapy sessions and ECT administration.

There is excellent coordination between the Postgraduate Medical Institute and the three undergraduate medical schools with active involvement of faculties of these schools in teaching DPM students and in examining them in examinations conducted by the University of the Punjab which awards the Diploma to those who qualify. The DPM is recognised as a minor diploma by the Pakistan Medical \& Dental Council and DPM psychiatrists are eligible for appointment as 'psychiatrists' at district headquarter hospitals.

During the past five years, 119 doctors were admitted to the DPM course from all over the country, 12 female and 107 male. Forty per cent have passed the DPM Part II examination and another $30 \%$ have passed Part I only.

The government of Pakistan has decided to appoint these DPM psychiatrists at district headquarter hospitals, and later at Tehsil Hospital, to provide psychiatric services to psychiatric patients and drug dependent persons on their doorstep. 
With increasing awareness of mental health among people and the availability of DPM psychiatrists in the rural areas, patients, instead of going to 'Pirs' (spiritual healers) and 'faith healers', have started demanding psychiatric facilities. The menace of drug dependence had been a top priority of the government and an important reason for the creation of jobs for district psychiatrists in the government Health Department. The drug addiction treatment centres are being set up at district headquarter hospitals which will treat drug dependents and also provide psychiatric care to psychiatric patients in the area. As more locally trained psychiatrists become available who are willing to work at these district hospitals, the psychiatric facilities will be extended to Tehsil hospitals and later to rural health centres and primary care centres. Thus training of psychiatrists locally helps the government save money and time in postgraduate psychiatric education and the trainee psychiatrist to learn psychiatry in his cultural environments. The DPM has helped Pakistan extend psychiatric facilities to the doorstep of the common man.

Ijaz Haider Head of Department and Professor of Psychiatry, Postgraduate Medical Institute, 6 Birdwood Road, Lahore-3, Pakistan

\section{Speech and Language Disorders in Psychiatry Edited by Andrew Sims}

Descriptive psychopathology provides a different and refreshing approach to the understanding of mental illness. Speech and Language Disorders in Psychiatry starts from this standpoint and links research into speech and language disorder with clinical psychiatry. In particular, it provides a detailed and comprehensive account of current research into schizophrenic speech and language disorder. The authors of this collection of articles are leading authorities in psychiatry, neurology, psychology and communications.

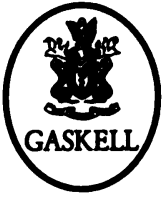

$£ 20.00 \bullet 206 p p . \bullet$ Hardback $1995 \bullet$ ISBN 0902241796

Available from bookshops and from the Publications

Department, Royal College of Psychiatrists, 17 Belgrave Square,

London SW1X 8PG (Tel. 0171-235 2351 extension 146) 